\title{
A serological relationship between mumps and sendai viruses*
}

\author{
BY P. S. GARDNER \\ Public Health Laboratory, Newcastle upon Tyne
}

(Received 27 March 1960)

\section{INTRODUCTION}

The first evidence that there might be a relationship between mumps and Sendai (now parainfluenza 1) viruses was given in this country by Gardner (1957) and in the United States by DeMeio \& Walker (1957). The object of this paper is to present further evidence of this relationship by describing the serological findings in sixty-six cases of clinical mumps and results of serological surveys of antenatal sera and blood transfusion sera. These investigations were carried out during 1956 and 1957.

\section{MATERIALS AND METHODS}

Sera

Sixty-six pairs of acute and convalescent sera from cases of mumps were tested for complement-fixing antibodies against Sendai and mumps virus particle antigens. A large proportion of these cases were tested with mumps soluble antigen. When there was clinical evidence of involvement of the central nervous system, the sera were also tested with the antigen of lymphocytic choriomeningitis (LCM). The examination of sera for antibodies to leptospira was done by the Standards Laboratory at Colindale.

The 362 blood donor sera came from various towns in south and south-west England : 46 sera came from donors in Reading, 71 from Newbury, 99 from Oxford, 48 from Towcester, 49 from Cirencester and 49 from Purton. All these sera were tested for complement-fixing antibodies against Sendai and mumps virus particle (V) antigens.

Nine hundred and seventy-eight sera of women living in the Edgware area of Greater London who were attending antenatal clinics were also examined for complement-fixing antibodies against Sendai and mumps virus particle antigens.

\section{Antigens}

Sendai and mumps virus particle antigens used were the same as those employed by White, Gardner \& Simpson (1957). The mumps soluble antigen was prepared from the membranes of the eggs used in the preparation of mumps virus particle antigen. The strain of lymphocytic choriomeningitis virus used was W.E. 123, which was obtained from Dr Smadel in U.S.A. in 1947.

* This paper formed part of a thesis approved by the University of London for the award of the Degree of M.D. 


\section{Serological tests}

The complement-fixation tests with the Sendai and the mumps $\mathrm{V}$ antigens were carried out by the method described by White et al. (1957), but the c.F.T.'s with the L.C.M. and the mumps soluble antigens were done by an overnight fixation method using $2 \mathrm{MHD}$ of complement. The serum, antigen, complement mixtures were placed in the $+4^{\circ} \mathrm{C}$. refrigerator where they remained overnight. The next morning the racks of tubes were transferred to the bench and allowed to stand at room temperature for $30 \mathrm{~min}$. before the haemolytic system was added to each tube. The racks were placed in the $37^{\circ} \mathrm{C}$. water-bath for half an hour; they were shaken after 5 and $15 \mathrm{~min}$. incubation. After removal from the water-bath the racks were stood on the bench to allow the unhaemolysed red cells to settle and to facilitate the reading of the end-point, which was taken as the tube showing not more than $25 \%$ haemolysis.

\section{RESULTS}

\section{Examination of sera from patients suffering from mumps}

This group consisted of patients suffering from simple uncomplicated clinical mumps or those in which the infection was complicated by signs of meningitis, orchitis or pancreatitis. Many of the patients presented signs of meningeal involvement, and sera from all such patients were examined for complement-fixing antibodies with mumps $V$ antigen, mumps soluble antigen, the antigen of L.C.M. and also for the presence of antibodies to the leptospiral group of organisms. If there were no meningeal signs, they were examined with only the mumps antigens. All were examined for the presence of complement-fixing antibodies against Sendai antigen.

Table 1. Complement-fixation Test.

\begin{tabular}{crrrrrr} 
& \multicolumn{1}{c}{ Patient } & \multicolumn{1}{c}{ Sendai } & $\overbrace{1}$ & \multicolumn{2}{c}{ Mumps } & $\overbrace{1}$ \\
1 & $<8$ & $<8$ & 16 & 64 & 80 & 80 \\
2 & $<4$ & $<4$ & $<4$ & 32 & $<20$ & 40 \\
3 & - & $<8$ & 8 & 64 & $<20$ & 160 \\
4 & $<4$ & $<4$ & $<4$ & 8 & - & $<20$ \\
5 & - & $<8$ & 16 & 64 & 160 & 320 \\
6 & 8 & 8 & 16 & 64 & 40 & 160 \\
7 & 16 & 16 & 8 & 64 & 40 & 40 \\
8 & 8 & 8 & 8 & 64 & 80 & 80 \\
9 & $<4$ & $<4$ & 16 & 64 & 80 & 320 \\
10 & 8 & 8 & $<4$ & 8 & $<20$ & 40 \\
11 & - & $<8$ & 4 & 32 & 40 & 80 \\
12 & $<8$ & $<8$ & $<8$ & 64 & $<20$ & 40 \\
13 & $<8$ & $<8$ & 16 & 64 & - & - \\
14 & 8 & 16 & $<4$ & 64 & $<20$ & 40 \\
15 & 8 & 32 & 32 & 64 & 40 & 80 \\
16 & $<8$ & 128 & 16 & 64 & 40 & 320 \\
17 & $<8$ & 64 & $<8$ & 128 & - & - \\
18 & $<8$ & 128 & $<8$ & 256 & - & - \\
19 & $<8$ & 32 & $<8$ & 128 & - & - \\
20 & $<8$ & 16 & 8 & 128 & 20 & 80
\end{tabular}


Table 1 (cont.)

\begin{tabular}{|c|c|c|c|c|c|c|}
\hline \multirow[b]{2}{*}{ Patient } & \multicolumn{2}{|c|}{ Sendai } & \multicolumn{2}{|c|}{ Mumps V } & \multicolumn{2}{|c|}{ Mumps S } \\
\hline & 1 & 2 & 1 & 2 & 1 & 2 \\
\hline 21 & $<4$ & 8 & $<4$ & 64 & $<20$ & 160 \\
\hline 22 & 4 & 16 & $<4$ & 16 & $<20$ & 40 \\
\hline 23 & $<4$ & 16 & 16 & 64 & $<20$ & 40 \\
\hline 24 & $<4$ & 32 & $<4$ & $\geqslant 32$ & $<20$ & 80 \\
\hline 25 & 4 & 16 & $<4$ & 64 & $<20$ & 40 \\
\hline 26 & $<4$ & 8 & $<4$ & 16 & $<20$ & 40 \\
\hline 27 & 4 & 16 & 8 & 32 & - & - \\
\hline 28 & $<2$ & 8 & 32 & 256 & 160 & 320 \\
\hline 29 & 4 & 16 & 16 & 64 & $<20$ & 160 \\
\hline 30 & 8 & 64 & 4 & 64 & 20 & $\mathbf{4 0}$ \\
\hline 31 & $<4$ & 32 & $<4$ & 16 & $<20$ & 20 \\
\hline 32 & 4 & 16 & 4 & $\geqslant 32$ & $<20$ & 80 \\
\hline 33 & 16 & 64 & 16 & 64 & 80 & 80 \\
\hline 34 & $<4$ & 32 & $<4$ & 64 & 40 & 160 \\
\hline 35 & 16 & 64 & 8 & 64 & 20 & 80 \\
\hline 36 & $<4$ & 8 & 16 & 64 & 320 & 160 \\
\hline 37 & 4 & 8 & 8 & 16 & $<20$ & 40 \\
\hline 38 & $<8$ & 32 & $<8$ & 64 & 20 & 80 \\
\hline 39 & $<4$ & 8 & 32 & 128 & $<20$ & 20 \\
\hline 40 & $<4$ & 8 & 16 & 64 & 80 & 80 \\
\hline 41 & 16 & $\geqslant 64$ & 8 & $\geqslant 64$ & 40 & 40 \\
\hline 42 & $<4$ & 8 & $<4$ & $\geqslant 32$ & 20 & 20 \\
\hline 43 & $<4$ & 32 & 16 & 64 & 20 & 40 \\
\hline 44 & 4 & $\geqslant 64$ & 8 & $\geqslant 64$ & 20 & 80 \\
\hline 45 & 4 & 16 & 4 & 64 & 40 & 80 \\
\hline 46 & 4 & 64 & 16 & $\geqslant 64$ & 80 & 160 \\
\hline 47 & 8 & 32 & 8 & 16 & $<20$ & 20 \\
\hline 48 & $<4$ & $<4$ & $<4$ & $\geqslant 64$ & $<20$ & 40 \\
\hline 49 & $<4$ & $<4$ & $<4$ & $\geqslant 64$ & $<20$ & 80 \\
\hline 50 & $<8$ & $<8$ & $<8$ & 128 & 40 & 320 \\
\hline 51 & $<8$ & $<8$ & 8 & 32 & 20 & 20 \\
\hline 52 & $<8$ & $<8$ & $<8$ & 32 & $<20$ & 40 \\
\hline 53 & $<8$ & $<8$ & $<8$ & 16 & $<20$ & 20 \\
\hline 54 & $<4$ & $<4$ & $<4$ & $\geqslant 64$ & 20 & 40 \\
\hline 55 & $<2$ & $<2$ & $<2$ & 16 & $<20$ & 20 \\
\hline 56 & $<8$ & $<8$ & $<8$ & 512 & 20 & 160 \\
\hline 57 & $<4$ & $<4$ & $<4$ & 32 & $<20$ & 40 \\
\hline 58 & $<8$ & $<8$ & 8 & 32 & 20 & 20 \\
\hline 59 & 4 & 8 & 16 & 64 & 160 & 160 \\
\hline 60 & 16 & 32 & 4 & 16 & $<20$ & 80 \\
\hline 61 & 4 & 8 & $<4$ & 64 & $<20$ & 40 \\
\hline 62 & $<4$ & 16 & $<4$ & $\geqslant 64$ & $<4$ & 32 \\
\hline 63 & $<4$ & 16 & 16 & $\geqslant 64$ & $<20$ & 160 \\
\hline 64 & 16 & $\geqslant 64$ & 16 & 64 & 20 & 80 \\
\hline 65 & $<4$ & 4 & 4 & $\geqslant 64$ & - & $<20$ \\
\hline 66 & $<4$ & 4 & $<4$ & 8 & $<20$ & 40 \\
\hline
\end{tabular}

Figures are given as the reciprocal of the dilution of the sera. 1 indicates 'acute' specimen of serum; 2 indicates 'convalescent' specimen of serum; - indicates not tested; mumps $V$ indicates mumps virus particle antigen; mumps $\mathrm{S}$ indicates mumps soluble antigen. Where appropriate, sera were tested with the antigen of lymphocytic choriomeningitis by the complement-fixation test and by an agglutination test for the leptospiral group of organisms. These tests were all negative. 
Complement-fixing antibodies against Sendai and mumps particle antigens were detected by the short complement-fixation test, while antibodies to mumps soluble antigen and the antigen of L.C.M. were detected by the long fixation test. Fourfold or greater increases in antibodies fixing complement were considered to be positive. The results are shown in Table 1 .

\section{Examination of blood transfusion donors and antenatal patients' sera}

The results of the examination of these sera are summarized in Table 2. The patients were examined with mumps virus particle antigen and Sendai antigen only. A titre of $1 / 8$ or greater was taken as positive.

Table 2

$\begin{array}{lccrcccc} & \mathbf{S}^{+} \mathbf{M}^{+} & \% & \mathrm{~S}^{+} \mathbf{M}^{-} & \% & \mathbf{S}^{-} \mathbf{M}^{+} & \% & \text { Total } \\ \text { Transfusion sera } & 18 & 5 & 37 & 10 & 13 & 4 & 362 \\ \text { Antenatal sera } & 85 & 9 & 171 & 17 & 35 & 4 & 978\end{array}$

$\mathrm{S}^{+}$indicates Sendai antibodies $\geqslant 1 / 8 ; \mathrm{S}^{-}$indicates Sendai antibodies $<1 / 8 ; \mathrm{M}^{+}$indicates mumps antibodies $\geqslant 1 / 8 ; \mathrm{M}^{-}$indicates mumps antibodies $<1 / 8$.

\section{Examination of standard sera and patients' sera who were suffering from mumps}

The final investigation consisted of examining the standard control sera and patients" sera by the chequer-board method with both Sendai and mumps virus particle antigens for the presence of complement-fixing antibodies. Only five pairs of patients' sera were in sufficient quantity to be examined fully by the chequerboard technique, based on the original work of Dean \& Webb (1926). These latter sera comprised one pair which had a rising antibody titre to mumps virus particle antigen only and four pairs which had rising antibody titres to both Sendai virus antigen and mumps virus particle antigen.

When mumps virus particle antigen and Sendai antigen were titrated by chequer-board technique against standard mumps and Sendai antisera, it was found that mumps antigen did not react with the Sendai antiserum but did with its own antiserum showing an optimum of about $1 / 80$. Sendai antigen reacted with both standard mumps and Sendai antisera and in both sera showed an optimum of $1 / 20$.

Chequer-board titrations on one pair of sera from a case of mumps showed a complete absence of antibodies against Sendai antigen but mumps antibodies were present in an increasing amount.

Four other paired sera from cases of mumps, however, showed at least a fourfold or greater increase in antibodies to both Sendai and mumps antigens. Both antigens gave their expected optima which demonstrated the independent action of the two antibodies.

\section{DISCUSSION}

It has been known for some time that mumps bears an antigenic relationship to Newcastle disease virus (Jungherr, Luginbuhl \& Kilham (1949); later Chanock (1956), in the U.S.A., found a relationship between his 'croup-agent' and mumps 
virus. The results which have been presented in this paper confirm the existence of an antigenic relationship between mumps and Sendai virus.

Table 1 gives the results of the examination of sixty-six pairs of sera from patients suffering from mumps. These sera had all been tested with Sendai and mumps virus particle antigens. The results divided patients into two groups: those whose sera reacted with both Sendai and mumps virus particle antigens and those which reacted with only mumps virus particle antigen. For the purpose of this analysis, the occasional case which showed only a twofold rise of antibodies fixing complement with Sendai antigen was counted as non-rising.

There were thirty-one cases which showed a fourfold or greater increase in antibodies fixing complement with mumps virus particle antigen but no increase of complement-fixing antibodies when tested with Sendai antigen. Thirty-five cases showed a fourfold or greater rise of antibodies fixing complement with both Sendai and mumps virus particle antigens.

These two groups of patients of approximately equal size and both infected with mumps showed quite a different antibody response. Chequer-board titration of the two antigens against mumps sera have clearly demonstrated that both antibodies, when present, react independently with the two antigens and give the expected optimum of these two antigens.

There are three possible explanations of the formation of the two antibodies during mumps infection. The first is that all mumps viruses are of the same antigenic structure and all contain some Sendai antigen. The Sendai antigen content is small and only about $50 \%$ of the population are sensitive and react to it by showing a rise of antibodies. Another explanation is that there are two varieties of mumps virus causing the illness, one containing mumps only and the other containing a mixture of mumps and Sendai antigens. The third possibility is that mumps virus contains mumps antigen only and that when it infects patients who have had a previous experience of Sendai virus it calls forth an anamnestic type of response.

The results of the survey of antenatal and blood transfusion sera must be carefully considered before it is possible to decide which of these hypotheses is the most probable.

Of the 978 antenatal sera examined, 681 were negative to both Sendai and mumps virus particle antigens at a titre of $1 / 8$. Thirty-five were positive to mumps virus particle antigen only and 171 to Sendai only at a titre of $1 / 8$ or greater; 85 were positive to both at a titre of $1 / 8$ or greater (Table 2 ).

Of the 362 blood transfusion sera, 294 were negative to both Sendai and mumps virus particle antigens, 13 were positive to mumps virus particle antigen and 37 to Sendai only and 18 were positive to both Sendai and mumps virus particle antigens. Titres of $1 / 8$ or greater were again counted as positive (Table 2).

Both groups of sera showed that Sendai antibodies occurred by themselves fairly commonly, $10 \%$ in the blood transfusion donors and $17 \%$ in the antenatal group. Both showed the same percentage of persons with mumps antibodies only, $4 \%$. Mumps and Sendai antibodies occurred together in the sera of both groups, $5 \%$ of donor sera and $9 \%$ of antenatal sera. The percentages quoted above are given 
to the nearest whole number. It should be noted that among the blood donors, the group with both Sendai and mumps antibodies was approximately equal in size to the group with only mumps antibodies. This finding is similar to that in patients suffering from mumps where the two groups, i.e. those with mumps antibodies only and those with both mumps and Sendai antibodies, were also of approximately equal size. Compared with the blood transfusion donors' sera the antenatal sera showed a higher percentage of positives in the group with Sendai complementfixing antibodies and also in the group with both Sendai and mumps antibodies. These higher figures might be accounted for by the fact that this was a highly select group. They were all females between the ages of 16 and 45 years with an average age of 20-30 years. Half were multipara and it was, therefore, highly probable that these persons might have received antigenic stimuli from exposure to the infections their older children acquired in school.

White et al. (1957) showed that within 3 months of infection with Sendai virus, complement-fixing antibodies had fallen rapidly. We can, therefore, assume that patients showing Sendai antibodies must have been recently infected. Nevertheless, six out of thirteen patients who had a titre of $1 / 8$ or greater of Sendai complement-fixing antibodies in the acute specimen of serum showed no significant change in titre in the convalescent specimen despite a minimum of a fourfold or greater rise in complement-fixing antibodies against mumps virus particle antigen (Table 1 , cases $6,7,8,10,14$ and 60 ). This discounts the possibility of mumps infection, giving an anamnestic type of response.

The evidence presented showed that a proportion of cases of mumps infection developed both mumps and Sendai antibodies. This is also reflected in the general community where a similar proportion of persons possessing both antibodies was found. Patients suffering from Sendai infections, on the other hand, do not develop antibodies against mumps antigen (Gardner, 1957). This may be because any Sendai component of mumps virus is present in too small an amount to react with Sendai antibodies or is masked by the major antigens. While it is not impossible that patients might get dual infections, it is highly unlikely that such a high proportion $(50 \%)$ of mumps patients tested should have also had a recent Sendai infection. We must, therefore, assume that infection with the mumps virus in $50 \%$ of cases results in the appearance of Sendai antibodies.

The only other hypothesis is that there are two antigenic varieties of mumps virus, one sharing an antigenic component that is also contained in Sendai virus and the second not. This is a theoretical possibility but it does not seem likely that there would always be an equal proportion of infection with these two hypothetical agents which would be the only way of accounting for the findings. Further it could be supposed that one strain might result in more severe infections with complications, yet in practice patients with parotitis, meningitis and orchitis still gave $50 \%$ with mumps antibodies only and $50 \%$ with both mumps and Sendai antibodies.

It is clear that a great deal more work needs to be done on the basic structure of mumps virus. Many more strains should be isolated so that they may be examined, especially for their content of Sendai antigen. 


\section{SUMMARY}

Sixty-six paired sera from patients suffering from mumps were examined with Sendai and mumps virus particle antigen: $50 \%$ showed a rise of complementfixing antibodies to mumps virus particle antigen only and the rest to both antigens.

This relationship was further substantiated by the occurrence of both antibodies in a proportion of the sera of 362 blood transfusion donors and 978 sera from antenatal patients.

The occurrence of both antibodies in patients' sera is discussed and the conclusion is reached that one of the components of the mumps antigen complex is indistinguishable from the essential components of the Sendai virus.

I am indebted to the Maternity Department of the Edgware General Hospital for supplying the antenatal sera, and to Dr Preston of the Regional Transfusion Centre, Oxford, for the blood donor sera.

\section{REFERENCES}

Chanock, R. M. (1956). J. exp. Med. 104, 555.

Dean, H. R. \& WebB, R. A. (1926). J. Path. Bact. 29, 473.

DEMEIO, J. L. \& WALKER, D. L. (1957). J. Immunol. 78, 465.

GaRDNER, P. S. (1957). Brit. med. J. i, 1143.

Jungherr, R., Luginbuhl, R. E. \& Kilham, L. (1949). Science, 110, 333.

White, G. B., Gardner, P. S. \& Simpson, R. E. H. (1957). Brit. med. J. i, 381. 